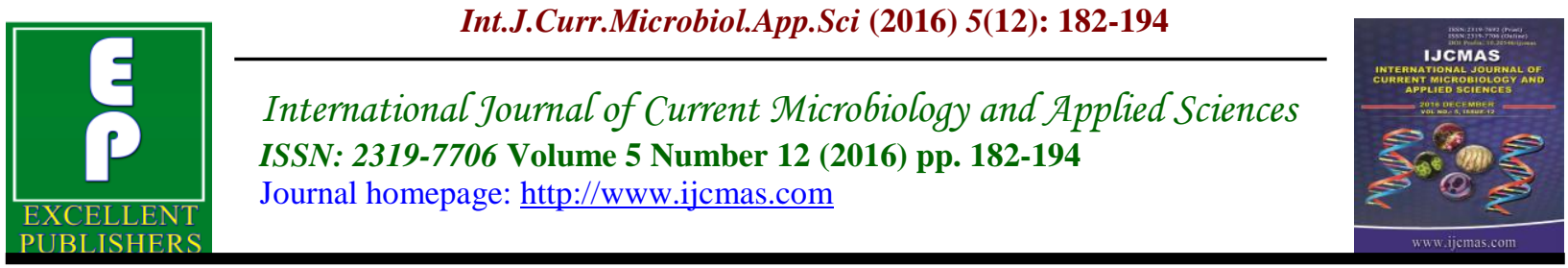

Original Research Article

http://dx.doi.org/10.20546/ijcmas.2016.512.020

\title{
Trends in Gonococcal Antimicrobial Resistance in Cameroon: Before and After the Launching of the Gonococcal Antimicrobial Surveillance Program
}

\author{
Ariane Nzouankeu, Antoinette Ngandjio, Carole Tayimetha, Gaëlle Tchouwa, \\ Marcelle Abanda, Esther Sokeng, Marie-Christine Fonkoua
}

\author{
Laboratory of bacteriology, Pasteur Centre of Cameroon, Yaounde, Cameroon \\ *Corresponding author
}

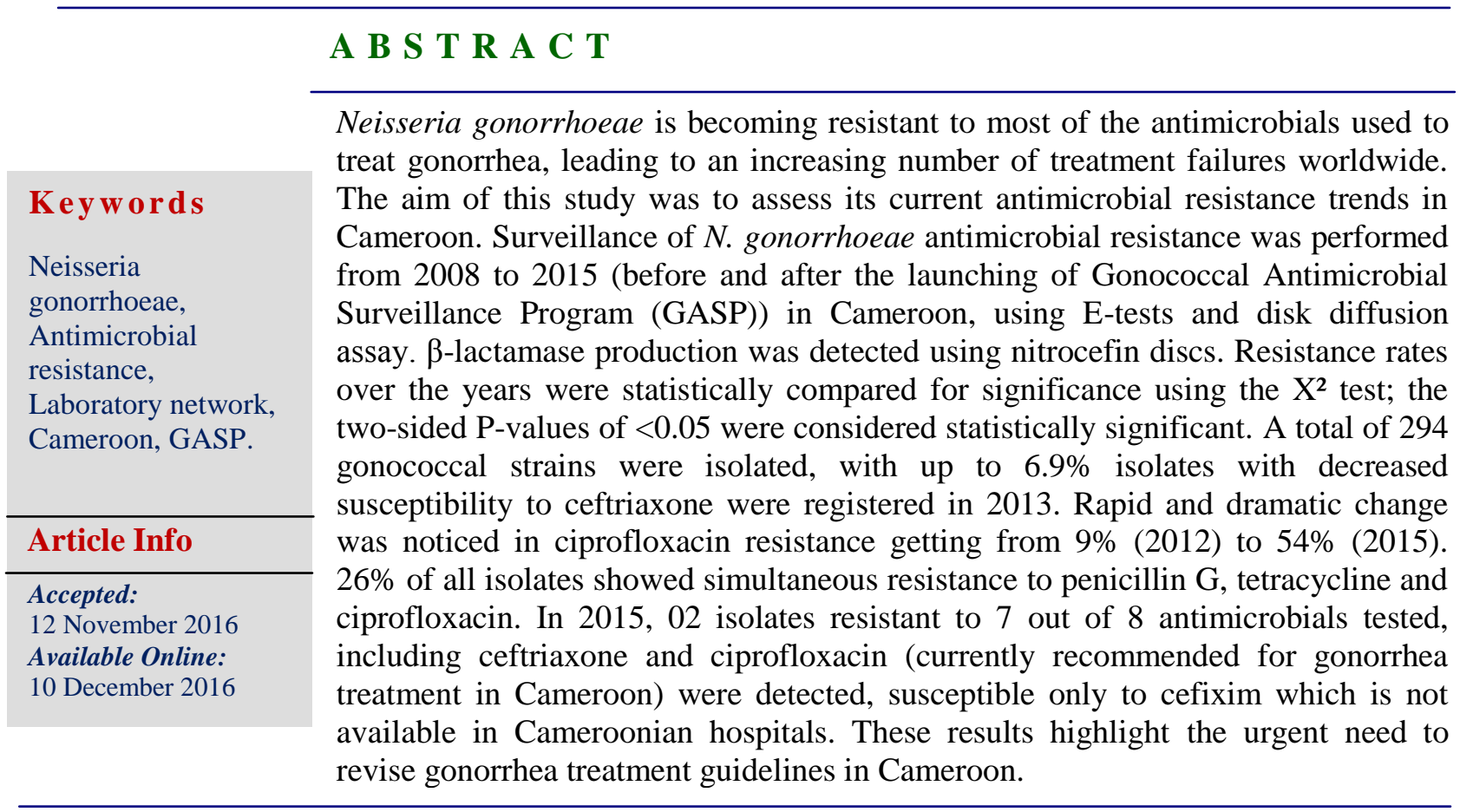

\section{Introduction}

Gonorrhea is among the most prevalent sexually transmitted diseases throughout the world, resulting in substantial morbidity and economic costs. Its causative agent, Neisseria gonorrhoeae predominantly infects human urogenitaltract, causing cervicitis, urethritis, and rectal infections. The World Health Organization reports that gonococcal infections represent 106 million of the estimated 498 million new cases of curable Sexually Transmitted Infections (STI) occurring worldwide each year (WHO, 2012).

Accurate diagnosis of gonorrhea is based on gonococcus identification by PCR or through culture followed by antimicrobial susceptibility testing. However, in SubSaharan Africa many laboratories cannot afford these techniques and even when available, patients may not be able to pay 
the price of analysis. Consequently, to interrupt the chain of transmission of this disease and prevent occurrence of complications in such countries, treatment is often based on syndromic approach. In Cameroon, national guidelines, suggest the use of ciprofloxacin coupled with doxycycline for treatment of any suspicious case of gonorrhea (MINSANTE, 2007) in practice a variety of antimicrobials are used (cefixime, ceftriaxone, azithromycin, tetracycline), usually with no respect of dosage, contributing to the emergence of treatment failures.

The recently observed resistance of $N$. gonorrhoeae to ceftriaxone as well as the emergence of multidrug resistant Neisseria gonorrhoeae strains has placed antimicrobial resistance (AMR) surveillance in the heart of public health priorities worldwide (Ohnishi et al., 2011; Unemo et al., 2012; Whiley et al., 2012; Kirkcaldy et al., 2013; Faye et al., 2015). In response to this threat, WHO set up in 1990, the Gonococcal Antimicrobial Surveillance Program (GASP) to helps track emerging resistant strains, monitor changing patterns of susceptibility, and in view to update treatment recommendations on regular basis (WHO, 1990).The central Africa GASP was launched in 2011 during a meeting in Harare (Zimbabwe), and Centre Pasteur Cameroon (CPC) was designated as the reference laboratory for gonococcal antimicrobial surveillance in this region (Ndowa et al., 2013). Activities of Central Africa GASP began in Cameroon in August 2012 as a surveillance platform to monitor antimicrobial resistant urogenital $N$. gonorrhoeae isolates among patients seen at health care centers and hospitals in the country. The aim of this study was to assess its current antimicrobial resistance trends in Cameroon and highlight the impact of the Gonococcal Antimicrobial Surveillance Program (GASP) on data collection

\section{Materials and Methods}

\section{Participating laboratories}

The Cameroon-GASP was launched in 2012 with a panel of 20 laboratories, as a sentinel surveillance network responsible of samples collection, N. gonorrhoeae identification and antimicrobial susceptibility testings (AST). Sentinel laboratories were divided into 2 groups: healthcare centers laboratories with no culture capacities, had to provide shortly after genital sampling, gram staining smears and inoculated culture media in Petri dishes.

-hospital laboratories able to realize culture and identification, had to provide only strains for AST and storage.

This network was steered by the Bacteriology Laboratory of CPC (reference laboratory), which was in charge of gram staining smears control, confirmation of all gonococcal identification, AST and storage at $-80^{\circ} \mathrm{C}$. CPC also collected $N$. gonorrhoeae from patients received on site.

\section{Samples collection and identification of $N$. gonorrhoeae}

Gonococcal isolates were collected from all patients with/without clinical signs (genital discharge) of gonorrhea, attending laboratories of the network. All samples (urethral for men and cervix for ladies) were handled as part of the routine laboratory analysis and no ethical approval was required. Gram staining smears were used for direct detection of $N$. gonorrheae and all samples were inoculated on chocolate media plates (with a Colombia agar base), then incubated at $37^{\circ} \mathrm{C}$ in $5 \% \mathrm{CO}_{2}$ for $24-48 \mathrm{~h}$, according to the French REMIC recommendations (REMIC, 2010). 
Identification of $N$. gonorrhoeae was done using API NH strips (BioMerieux).

\section{Antimicrobial susceptibility testing}

Antimicrobial susceptibility testings of all $N$. gonorrhoeae isolates were performed using both E-test methodfor the determination of Minimum Inhibitory Concentrations (MIC in $\mathrm{mg} / \mathrm{L})$ of penicillin $\mathrm{G}($ PenG), ceftriaxone (CFX), cefixime (CFM), and ciprofloxacin (CIP). MIC90 for each antimicrobial was defined as the smallest MIC value which inhibits growth of $90 \%$ of the tested isolates. On the other hand, disk diffusion assay was performed for spectinomycin (SPT: 100 $\mu \mathrm{g}$ ), tetracycline (TET: 30UI) and nalidixic acid (NA: 30 $\mathrm{g}$ ).

Because of the unavailability of Azithromycin E-tests trips, AST for this antimicrobial was done by disc diffusion assay (AZT: 15 $\mu$ g). In each case, a gonoccocal suspension of $1 \mathrm{McF}$ arland was inoculated on chocolate agar, then the E-test strips or discs were applied on the plates before incubation at $37^{\circ} \mathrm{C}$ in $5 \% \mathrm{CO}_{2}$ for 24 $48 \mathrm{~h}$. Breakpoints used to categorize isolates as sensitive, intermediate, or resistant were in accordance with the guidelines of Antibiogram Committee of the French Microbiology Society (CASFM, 2013). Haemophilus influenza ATCC 49766 was used as the quality control strain. Isolates with intermediate resistance were interpreted as resistant. Multidrug resistance (MDR) was defined as resistance to three or more antimicrobials from different classes.

\section{Detection of $\beta$-lactamases}

Productionof $\beta$-lactamases was detected witha chromogenic test, using nitrocefin (cefinase) discs (BioRad) according to the manufacturer's instructions.

\section{Statistical analysis}

The differences in resistance rates were statistically compared and tested for significance using the $\mathrm{X}^{2}$ test. The two-sided P-values of $<0.05$ were considered statistically significant.

\section{Results and Discussion}

Cameroon-gasp members and $N$. gonorrhoeae isolates

Among the 20 laboratories enrolled in this network, 10 (6 from healthcare centers, 3 from hospitals and CPC) participated actively, providing gonococcal isolates (table1). This active participation was correlated satisfactory results obtained by these laboratories at the proficiency testing.

From 2008 to 2015, a total of $294 N$. gonorrhoeae strains were isolated at CPC, among which 179 collected since the launching of GASP network in august 2012 (figure 1). This represents a twofold to threefold increase, compared to data obtained by CPC alone during the 2 previous years (figure1).

Trends in antimicrobial resistance of $N$. gonorrhoeae isolates

Though the annual numbers of gonococcal isolates were too small to draw conclusions from for each year, the trends and the cumulative were important enough to make observations.

\section{Penicillin G}

Resistance to penicillin $\mathrm{G}$ ranged between $77 \%$ (2010) to $100 \%$ (2011 and 2014). No significant variation $(\mathrm{P}$-value $=0.003)$ was registered in the resistance trend of $N$. gonorrhoeae isolates to this antimicrobial since the beginning of Cameroon-GASP activities (figure 3). MIC values of PenG in these resistant isolates were globally high, fluctuating between 0.064 to $32 \mathrm{mg} / \mathrm{l}$, with a MIC90 of $32 \mathrm{mg} / \mathrm{l}$. 
According to nitrocefin test, prevalence of Penicinillase producing $N$. gonorrhoeae (PPNG) was higher in 2014 (91.4\%), though it has been increasing ina non-significant way since the launching of the network (Pvalue $=0.07)($ figure 3$)$.

\section{Cefixime and ceftriaxone}

Determination of MIC values of cefixime started in CPC in August 2012 with Cameroon-GASP activities and up to now, no resistance to this drug was observed among $N$. gonorrhoeae isolates (MIC90< $0.016 \mathrm{mg} / \mathrm{l})$.

Throughout the study period, no significant variation $\left(\chi^{2}=8.8, p=0.23\right)$ was noticed for ceftriaxone MIC values ranging from 0,002to $0.125 \mathrm{mg} / \mathrm{l}$, with MIC90 0,002 mg/l. In 2013 and 2015, more than $6 \%$ gonococcal isolates showed decreased susceptibility to this antimicrobial (figure 3).

\section{Chloramphenicol}

Resistance rates of $N$. gonorrhoeae isolates to chloramphenicol in this study varied from $17.3 \%$ in 2008 to $11.3 \%$ in 2015 as saw-like teeth $\left(\chi^{2}=7.41, \mathrm{p}=0.38\right)$, with a peak noticed in 2012 (20\%). However, no resistance to this antimicrobial was observed in 2011 (figure 3).

\section{Tetracycline}

Over the study period, the highest percentage of tetracycline resistance was registered in 2011 when $100 \%$ of $N$. gonorrhoeae isolates exhibited resistance to this antimicrobial.

Since then, a non-significant decrease $\left(\chi^{2}\right.$ $=13.96, \mathrm{p}=0.003)$ in its resistance rates was noticed, reaching $84 \%$ in 2009

\section{Azithromycin}

From 2008 to 2011, no gonococcals isolate was resistant to azithromycin. But, since 2012 this resistance has been increasing, up to $22.4 \%$ in 2015 . However in 2014 , once again, no resistant isolates was registered.

\section{Spectinomycin}

In this study, the first $N$. gonorrhoeae strain resistant to spectinomycin was isolated in 2010.A year later (2011), no other spectinomycin resistant strain was observed. But, from 2012 to 2015, non-significant fluctuations have been observed, reaching up to $6.7 \%$ in 2014 .

\section{Quinolones}

Before activities of Cameroon-GASP, MIC values of ciprofloxacin were not determined; only nalidixic acid testing was performed by disc diffusion assay. Between 2012 and 2015, N. gonorrhoeae isolates have shown an increasing resistance to ciprofloxacin, reaching $54.3 \%$ in 2015 ; this increase was significant only from 2014to 2015( $p<0.0003)$.MIC values for this antimicrobial varied from 0,002 to $32 \mathrm{mg} / \mathrm{l}$ (MIC90: 0,067 mg/l).

\section{Resistance patterns}

Twenty five (25) different resistance patterns were obtained from these $N$. gonorrhoeae isolates from 2008 to 2015 (Table 2). Overall, $26 \%$ of all isolates were resistant to at least 3 classes of antimicrobials (MDR). This multidrug resistance was observed since 2008 , with a significant increase since 2013, reaching $47.6 \%$ in 2015.From 2008 to 2013, the most common resistance patterns in gonococcal isolates in Cameroon was Pen G-TET, but this pattern has now been replaced by PEN 
G - TET - CIP, exhibiting an additional resistance to ciprofloxacin. A gonococcal strain isolated in 2015 was resistant to all tested antimicrobials, except ceftriaxone.

Cameroon-GASP has been active for more than 3 years now and among the 10 active laboratories, CPC alone has generated 145 isolates out of 179. These low numbers of isolates from sentinel laboratories despite the trainings received by their laboratory staffs may be due to the widespread emphasis on syndromic management of gonorrhea among medical doctors working in these health facilities. On the other hand, in these laboratories the reference diagnosis test for N.gonorrhoeae is microscopical examination which was chosen because it can be performed easily while the patient is waiting, but usually requires skilled microscopists and well-maintained microscopes which may not be always available; hence complicating this diagnosis.

Contrary toother curable Sexually Transmitted Diseases such as syphilis and chlamydia infections for which therapeutic options remain effective, the effectiveness of individual case-management and diseasecontrol programsis compromised for gonorrhea because of the extent to which Neisseria gonorrhoeae isolates develop resistance to antimicrobials agents (Ohnishi et al., 2011; Whiley et al., 2012).

Wild type $N$. gonorrhoeae isolates are naturally resistant tolincosamides, colistineand polymyxin $\mathrm{B}$, therefore resistance to any other antimicrobials is acquired. Nowadays, the gonococcus is resistant to older, less expensive antimicrobials and to more recently introduced agents generating a worldwide worry. From 2008 to 2015, 15 N.gonorrhoeae isolates susceptible to all tested antimicrobials were registered showing that there is still low circulation of wild type gonococcal isolates in Cameroon. Resistance to penicillin is very frequent in gonococci and has been described on all continents (Kirkcaldy et al., 2013; Lahra, 2013; Sethi et al., 2013; Endimiani et al., 2014; Faye et al., 2015). In this study, 90\% of isolates had penicillin G MIC of $32 \mathrm{mg} / \mathrm{L}$, meaning this drugshould no longer be regarded as an alternative therapeutic agent among patients with gonorrhea in Cameroon.From 2008-2015, more than 70\% of gonococcal isolates were PenicinillaseProducing Neisseria gonorrhoeae(PPNG), thus expressingan inducible TEM-type $\beta$-lactamase, this is encoded on plasmids. This enzyme presence is systematically looked for $N$. gonorrhoeae because it hydrolyses the $\beta$-lactam ring of susceptible antibiotics such as penicillin. For $\beta$-lactamase negative strains resistant to penicillin $\mathrm{G}$, resistance might be due to the alteration of protein binding penicillin2 (PBP2) which is the target of this antimicrobial (Hyukmin et al., 2012).

Ceftriaxone (the injectable agent) and cefixime(the oral cephalosporin) are the third-generation cephalosporins recommended foruse in gonorrhea (Bignelland FitzGerald, 2011; Ison et al., 2013). In this study, up to 2010, no ceftriaxone resistance was observed. Itappeared in 2011 and reaches $6.3 \%$ in September 2015 with some strains exhibiting MIC as high as above $32 \mathrm{mg} / \mathrm{l}$.

This results suggests a threat in the efficacy of ceftriaxone in Cameroon. But, because ceftriaxone resistance rate was low and varied insignificantly throughout the study period it is too early to determine whether this resistance represents isolated cases or real and emerging pattern. Similar reports of $N$. gonorrhoeae isolates resistant to ceftriaxone, a drug considered for years as 
the last bullets in a single dose treatment arsenal against gonorrhea is increasing worldwide (Tapsall, 2009).

Contrary to data obtained in South-East Asia (Lahra, 2013). Norway (Unemo et al., 2010), Kenya in 2011(Supriya et al., 2011) and South Africa (Faye et al., 2015), all gonoccocal isolates in this study were fully susceptible to cefixim; this could be explained by the fact that this oral cephalosporin is not recommended nor used in Sexually Transmitted Infections cases in Cameroun (MINSANTE, 2007), Thereby this antimicrobial could be recommended in gonorrhea treatment in Cameroon.

With less than $40 \%$ overall susceptibility of $N$. gonorrhoeae isolates to tetracycline in this study, we noticed a low prevalence of tetracycline susceptible isolates in Cameroon. Similar results have been observed in Asia (Jabeen et al., 2011; Li et al., 2014), other African countries like South Africa (Dangor et al., 2010) and could be explained by the availability and the frequent use of this drug to treat many types of infections among which gonorrhea, Chlamydia and/or Ureaplasmal Mycoplasma infections.

However, it is not the drug of choice for treating gonorrhea, but in cases where syndromic management is applied and a clear difference between gonorrhea and another sexually transmitted infection is not established, tetracycline may be prescribed to the patients. This antimicrobial is usually administered for up to a week, thus exerting selective pressure on $N$. gonorrhoeae which later leads to development of resistance totetracycline.

Spectinomycin seems to have retained its effectiveness against $N$. gonorrhoeae in Cameroon ( $<9 \%$ resistant isolates) and could therefore be reconsidered in association with another drug as an alternative therapeutic option for patients with gonococcal urogenital infection who cannot tolerate cephalosporins (Lal Patel et al., 2006).

Eventhough it is not recommended for gonorrhea treatment in Cameroon, chloramphenicol is used, because of its reduced cost, ease of administration and clinical efficacy usually in resource-poor countries like Cameroon. As such, resistance of gonococcal isolates to this drug was evaluated and fluctuated under $20 \%$ from one year to another. Data concerning the resistance rate of this antimicrobial throughout the world are however sparse.

Though resistance to azithromycin was first reported in 1990, immediately after its introduction in gonorrhea treatment (Goire et al., 2014; Dillon et al., 2015), no resistance to this drug was registered among gonococci isolates in this study before 2012 . From 2012 to 2015 this resistance has been increasing up to $22 \%$, and could be related to increasing use of this drug since the availability of its generic form in the country; so the cost of this macrolide has been for years a limiting factor in using it to treat gonorrhea.

From $9 \%$ in 2012 to more than $50 \%$ ciprofloxacin -resistant gonococci isolates in 2015, this paper demonstrates a rapid and dramatic change in ciprofloxacin susceptibility among N.gonorrhoeae isolates in Cameroon within a short period.

Resistance to this antimicrobial spreads relatively fast, whereas it was introduced in treatment of gonorrhea in this country only since 2007. As such this spread could be the result of the overuse or misuse of this drug and, may have also been accelerated by the introduction of ciprofloxacin for the treatment of many other diseases in the country. 
Table.1 Details on the 10 active Cameroon-GASP laboratories

\begin{tabular}{|c|c|c|c|c|c|c|c|}
\hline \multirow[b]{2}{*}{ Laboratories } & \multirow[b]{2}{*}{ Study population } & \multirow[b]{2}{*}{ Level in the network } & \multicolumn{4}{|c|}{ Number of isolates/ per year } & \multirow[b]{2}{*}{ Total } \\
\hline & & & \begin{tabular}{|c} 
august- december \\
2012
\end{tabular} & 2013 & 2014 & 2015 & \\
\hline CPC & $\begin{array}{l}\text { all laboratories } \\
\text { patients } \\
\text { all laboratories }\end{array}$ & $\begin{array}{c}\text { Reference laboratory } \\
\text { Healthcare ce }\end{array}$ & 23 & 45 & 33 & 44 & 145 \\
\hline CASS & $\begin{array}{l}\text { patients } \\
\text { all laboratories }\end{array}$ & nter laboratory & 2 & 3 & 0 & 0 & 5 \\
\hline CHE/CNPS & $\begin{array}{l}\text { patients } \\
\text { all laboratories }\end{array}$ & $\begin{array}{l}\text { Hospitallaboratory } \\
\text { Healthcare center }\end{array}$ & 1 & 2 & 0 & 2 & 5 \\
\hline CMAE & $\begin{array}{l}\text { patients } \\
\text { all laboratories }\end{array}$ & $\begin{array}{c}\text { laboratory } \\
\text { Healthcare center }\end{array}$ & 0 & 2 & 0 & 0 & 2 \\
\hline CMAM & $\begin{array}{l}\text { patients } \\
\text { all laboratories }\end{array}$ & $\begin{array}{c}\text { laboratory } \\
\text { Healthcare center }\end{array}$ & 0 & 2 & 0 & 0 & 2 \\
\hline CSCM & $\begin{array}{l}\text { patients } \\
\text { all laboratories }\end{array}$ & $\begin{array}{c}\text { laboratory } \\
\text { Healthcare center }\end{array}$ & 1 & 8 & 4 & 0 & 13 \\
\hline GTL & $\begin{array}{l}\text { patients } \\
\text { all laboratories }\end{array}$ & laboratory & 0 & 1 & 0 & 0 & 1 \\
\hline GTLABO & $\begin{array}{l}\text { patients } \\
\text { all laboratories }\end{array}$ & $\begin{array}{l}\text { Hospitallaboratory } \\
\text { Healthcare center }\end{array}$ & 0 & 0 & 0 & 1 & 1 \\
\hline H Bethesda & $\begin{array}{l}\text { patients } \\
\text { all laboratories }\end{array}$ & $\begin{array}{c}\text { laboratory } \\
\text { Healthcare center }\end{array}$ & 0 & 0 & 3 & 0 & 3 \\
\hline HDCV & patients & laboratory & 0 & 1 & 1 & 0 & 2 \\
\hline \multicolumn{2}{|l|}{ Total } & & 27 & 64 & 41 & 47 & 179 \\
\hline
\end{tabular}


Table.2 Resistance patterns of $N$. gonorrhoeae isolates from 2008-2015

\begin{tabular}{|c|c|c|c|c|c|c|c|c|c|}
\hline Resistance patterns & 2008 & 2009 & 2010 & 2011 & 2012 & 2013 & 2014 & 2015 & total \\
\hline Susceptible to all antimicrobials & $1(4.5 \%)$ & $1(3.8 \%)$ & $3(16.7 \%)$ & $\mathbf{0}(\mathbf{0 \%})$ & $\begin{array}{c}3 \\
(12.5 \%) \\
\end{array}$ & $3(8.6 \%)$ & $0(0 \%)$ & $4(9.5 \%)$ & $15(7.1 \%)$ \\
\hline Resistant to 1 class of antimicrobial & $1(4.5 \%)$ & $6(27.1 \%)$ & $2(11.1 \%)$ & $0(0 \%)$ & $0(0 \%)$ & $3(8.6 \%)$ & $0(0 \%)$ & $8(19 \%)$ & $20(9.5 \%)$ \\
\hline PEN G & 1 & 5 & 1 & 0 & 0 & 2 & 0 & 4 & 13 \\
\hline NA* & 0 & 0 & 1 & 0 & 0 & 0 & 0 & 0 & 1 \\
\hline CIP & 0 & 0 & 0 & 0 & 0 & 1 & 0 & 1 & 2 \\
\hline TET & 0 & 1 & 0 & 0 & 0 & 0 & 0 & 3 & 4 \\
\hline Resistant to 2 class of antimicrobial & $16(72.7 \%)$ & $17(65.4 \%)$ & $10(55.5 \%)$ & $17(100 \%)$ & $18(75 \%)$ & $18(51.4 \%)$ & $15(55.6 \%)$ & $10(23.8 \%)$ & $121(57.3 \%)$ \\
\hline Pen G-TET & 16 & 17 & 8 & 16 & 17 & 13 & 10 & 3 & 100 \\
\hline Pen G-NA* & 0 & 0 & 1 & 0 & 0 & 0 & 0 & 0 & 1 \\
\hline PENG-SPT & 0 & 0 & 1 & 0 & 0 & 0 & 1 & 0 & 2 \\
\hline PEN G- CMP & 0 & 0 & 0 & 0 & 1 & 0 & 0 & 0 & 1 \\
\hline PEN G -CIP & 0 & 0 & 0 & 0 & 0 & 4 & 4 & 5 & 13 \\
\hline TET - CIP - & 0 & 0 & 0 & 0 & 0 & 0 & 0 & 1 & 1 \\
\hline PEN G - CFX -TET & 0 & 0 & 0 & 1 & 0 & 1 & 0 & 1 & 3 \\
\hline Multidrugresistance (MDR) & $4(18.2 \%)$ & $2(7.7 \%)$ & $3(16.7 \%)$ & $0(0 \%)$ & $3(12.5 \%)$ & $11(31.4 \%)$ & $12(44.4 \%)$ & $\begin{array}{c}20 \\
(47.6 \%) \\
\end{array}$ & $55(26.1 \%)$ \\
\hline PEN G-CMP-TET & 3 & 1 & 2 & 0 & 2 & 1 & 0 & 0 & 9 \\
\hline PENG -NA - TET $*$ & 0 & 1 & 0 & 0 & 0 & 0 & 0 & 0 & 1 \\
\hline PEN G - TET - CIP & 0 & 0 & 0 & 0 & 0 & 6 & 11 & 15 & 32 \\
\hline PEN G- SPT- TET & 0 & 0 & 0 & 0 & 0 & 1 & 0 & 0 & 1 \\
\hline PEN G - CFX- CMP - AZT & 0 & 0 & 0 & 0 & 0 & 1 & 0 & 0 & 1 \\
\hline PEN G -CMP -TET-NA* & 1 & 0 & 1 & 0 & 0 & 0 & 0 & 0 & 2 \\
\hline PEN G - CMP -AZT - TET & 0 & 0 & 0 & 0 & 0 & 1 & 0 & 0 & 1 \\
\hline PEN G - CMP - TET -CIP & 0 & 0 & 0 & 0 & 0 & 0 & 0 & 1 & 1 \\
\hline PEN G - AZT - TET- CIP & 0 & 0 & 0 & 0 & 0 & 0 & 0 & 1 & 1 \\
\hline PEN G - SPT - CMP - AZT- CIP & 0 & 0 & 0 & 0 & 1 & 0 & 0 & 0 & 1 \\
\hline PEN G - SPT - AZT- TET -CIP & 0 & 0 & 0 & 0 & 0 & 1 & 0 & 0 & 1 \\
\hline
\end{tabular}


Int.J.Curr.Microbiol.App.Sci (2016) 5(12): 182-194

PEN G -SPT- CMP- TET- CIP PEN G-CFX-SPT-CMP-CIP-AZT PEN G - CFX- CMP - AZT- TET - CIP

PEN G - SPT -CMP - AZT - TET- CIP

Total

\begin{tabular}{ccccccccc}
0 & 0 & 0 & 0 & 0 & 0 & 1 & 0 & 1 \\
0 & 0 & 0 & 0 & 0 & 0 & 0 & 1 & 1 \\
0 & 0 & 0 & 0 & 0 & 0 & 0 & 1 & 1 \\
0 & 0 & 0 & 0 & 0 & 0 & 0 & 1 & 1 \\
\hline $\mathbf{2 2}$ & $\mathbf{2 6}$ & $\mathbf{1 8}$ & $\mathbf{1 7}$ & $\mathbf{2 4}$ & $\mathbf{3 5}$ & $\mathbf{2 7}$ & $\mathbf{4 2}$ & $\mathbf{2 1 1}$ \\
\hline
\end{tabular}

*Up to 2011, nalidixic acid alone was tested, and no MIC was determine for ciprofloxacine

Fig.1 Numbers of N.gonorrhoeae isolates between 2008 and 2015

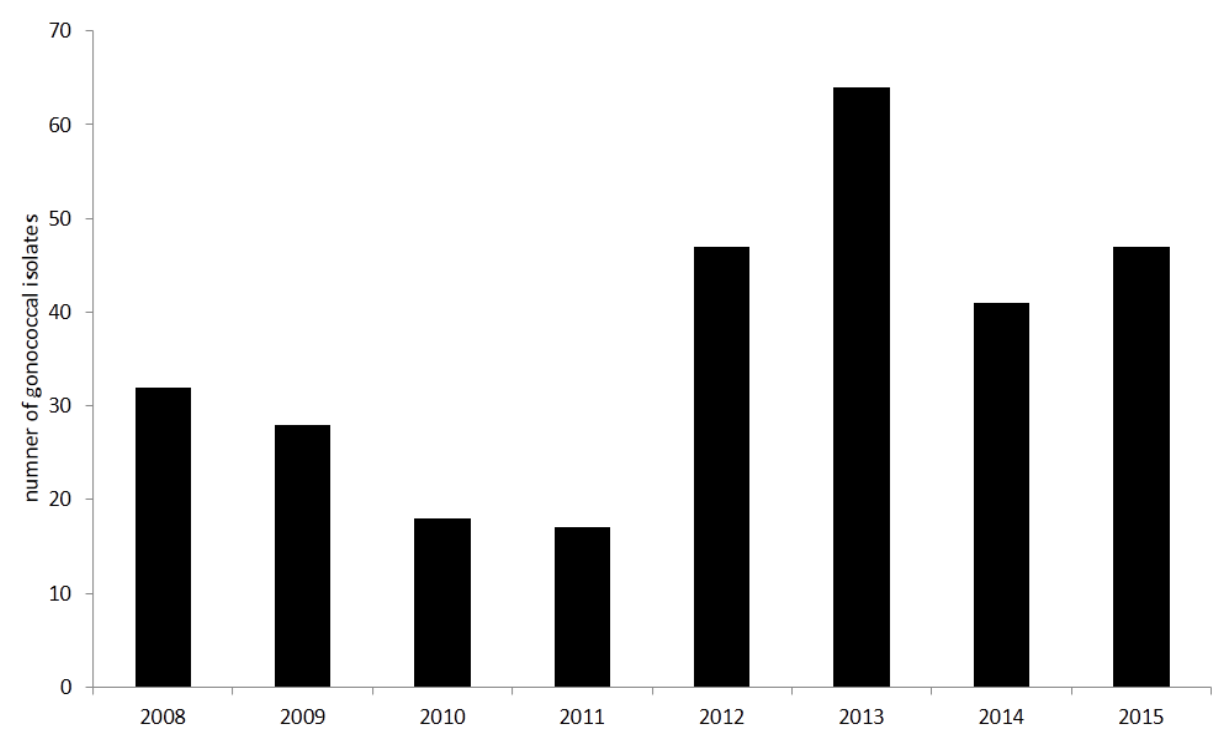




\section{Int.J.Curr.Microbiol.App.Sci (2016) 5(12): 182-194}

Fig.2 Antimicrobial resistance trends for Neisseria gonorrhoeae isolates. a): Trends in penicilline G resistance ceftriaxone decreased susceptibility and frequency of penicinillase producing N. gonorrhoeae isolates. b): Trends in chloramphenicol, tetracycline, azithomycin and spectinomycin resistance c): Trends in nalidixic acid and ciprofloxacin resistance.

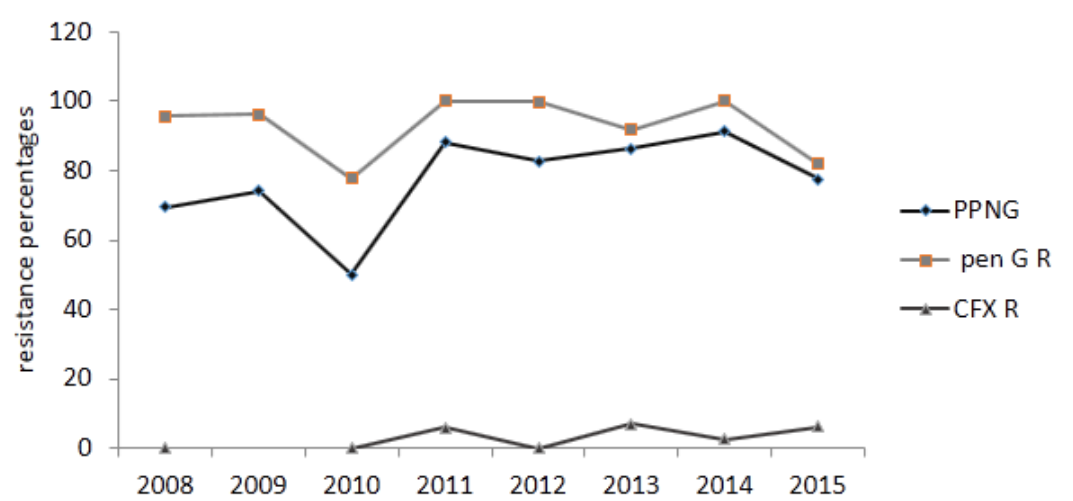

a)

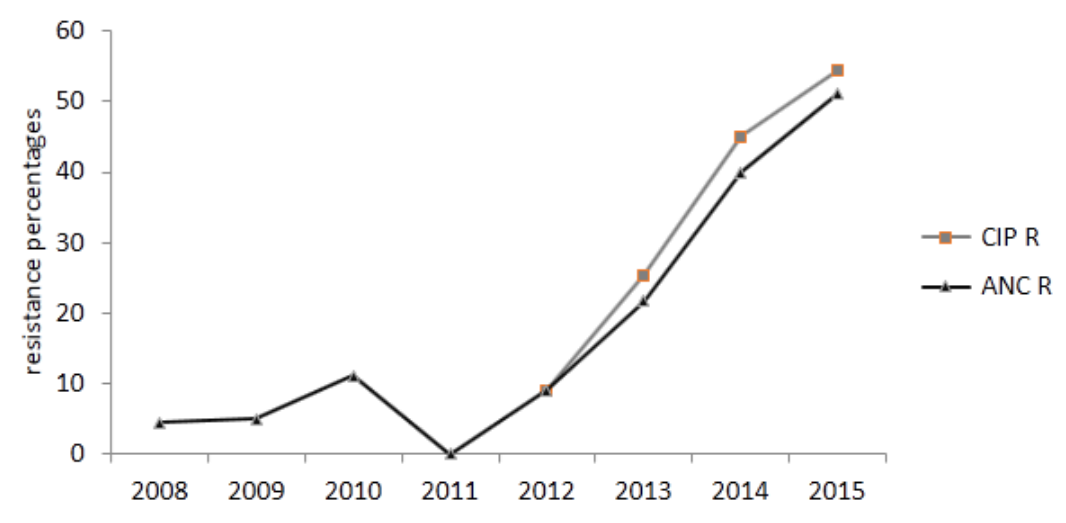

b)

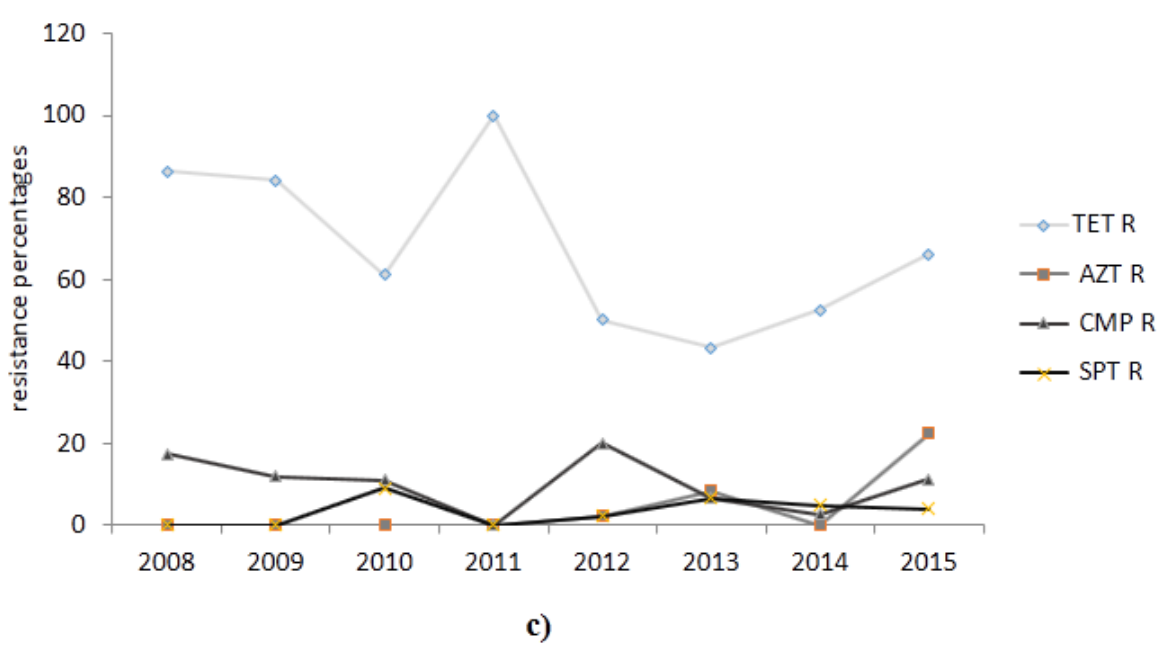


To avoid situation previously observed in some countries of South-East Asia (Lahra, 2013), were there is no more gonococcal isolate is susceptible to ciprofloxacin isolates, the use of this drug in gonorrhea in Cameroon needs urgent review and demonstrates the need of repeated and regular short-term studies in view to update therapeutic guidelines. These results are however different from those of China and Korea where resistance level were as high as $100 \%$ and $88 \%$ respectively (Bei et al., 2006; Hyukmin et al., 2012). Before 2014, as already observed by Cao et al (2008), the main resistant patternof $N$. gonorrhoeae isolateswas PenG-TET (penicillin, tetracyclin), but since 2014 with the increasing resistance to ciprofloxacin it has evolved to it is PenG-TET-CIP (penicillin, tetracyclin, ciprofloxacin). Similar data have been obtained in Switzerland, Morocco and others GASP WHO regions (south -East Asia and pacific), clearly showing that the use of these three antibiotics for the empirical treatment of gonococcal infections is no longer safe (Lahra, 2013; Sethi et al., 2013; Endimiani et al., 2014). Moreover, the isolation of 2 gonococci strains resistant to6 of the 7 tested antimicrobials is worrying and need to be monitored.

In conclusion, because of the close correlation between in vitro susceptibility to antibiotics and, therapeutic outcome of gonorrhea, these results highlight the crucial role of Cameroon-GASP Network in surveillance of N.gonorrhoeae antimicrobial drug resistance in Cameroon. As the number of antimicrobials available for treatment of gonorrhea is low and resistance emerges, these data should be notified to the Cameroonian Ministry of Public Health to help updating national gonorrhea treatment guidelines. To provide more accurate and representative data, the GASP network need to be stretched to others laboratories in Cameroon and Central Africa, and strengthened in the existing focal point laboratories, so as to contribute to the effective control of gonorrhea. Consequently, advocacy is needed to increase the resources allocated to control of antimicrobial resistant $N$. gonorrhoeae in Cameroon; the challenges include lack of equipments (incubators, $-80^{\circ} \mathrm{C}$ freezers), lack of funding and staff motivation. For further studies, it will be crucial to perform molecular analysis to better understand the dynamics of spread N.gonorrhoeae isolates and its resistance mechanisms, so as to target strains for control measures.

\section{Acknowledgments}

We are grateful to all laboratory staff of Cameroon-GASP for participating in this study, and to Adande Balbine for helping with statistical analysis.

\section{References}

Bei, W., J.S. Xu, C.X. Wang, Z.H. Mi, Y.P. $\mathrm{Pu}, \mathrm{M}$. Hui, K. Thomas, W. Link and Chan, C.Y. 2006. Antimicrobial susceptibility of Neisseria gonorrhoeae isolated in Jiangsu Province, China, with a focus on fluoroquinolone resistance. J. Med. Microbiol., 55, 1251-1255.

Bignell, C., and FitzGerald, M. 2011. UK national guideline for the management of gonorrhoea in adults. Int. J. STD \& AIDS, 22, 541-547

Cao, V., E. Ratsima, T.D. Van, R. Bercion, M.C. Fonkoua, V. Richard and Talarmin, A. 2008. Antimicrobial Susceptibility of Neisseria gonorrhoeae strains isolated in 20042006 in Bangui, Central African Republic; Yaoundé, Cameroon; Antananarivo, Madagascar; and Ho Chi Minh Ville and NhaTrang, Vietnam. Sex Transm. Dis., 35, 941945. 
CA-SFM (Antibiogram Commitee of the French Society for Microbiology). 2013. Paris, France, Official Statement 2013.

Dangor, Y., M. Jongh, A. Adam and Hoosen, A.A. 2010. Antimicrobial susceptibility patterns of gonococcal isolates in Pretoria, South Africa, over a 20-year period (1984-2004). South Afr. J. Epidemiol. Infect., 25, 10-13.

Endimian, A., Y.N. Guilarte, R. Tinguely, H. Faye-Ketteand Fonkoua, M.C. 2014. Characterization of Neisseria gonorrhoeae isolates detected in Switzerland (1998-2012): emergence of multidrug-resistant clones less susceptible to cephalosporins. BMC Infect. Dis., 14, 106-115

Faye, L.M., T. Apalata, and Sandeep, D. 2015. Emergence of Neisseria gonorrhoeaeIsolates with Decreased Susceptibility to Cefixime and Ceftriaxone from the Eastern Cape Province, South Africa. J. Innov. Res. Health Sc. Biotech., 1, 20-24.

Hyukmin, L., L. Kyungwon and Chong, Y. 2012. Antimicrobial Resistance of Neisseria gonorrhoeae isolated in Korea. J. Bacteriol. Virol., 42, 9-16.

Ison, C.A., C. Deal and Unemo, M. 2013. Current and future treatment options for gonorrhea. Sex Transm Infect., 89, $52-59$

Jabeen, K., S. Nizamuddin, S. Irfan, E. Khan, F. Malik and Zafar, A. 2011. Increasing Trend of Resistance to Penicillin, Tetracycline, and Fluoroquinolone Resistance in Neisseria gonorrhoeae from Pakistan (1992-2009). J. Trop. Med., Article ID $960501,1-5$

Kirkcaldy, R.D., S. Kidd, H.S. Weinstock, J.R. Papp and Bolan, G.A. 2013. Trends in antimicrobial resistance in Neisseria gonorrhoeae in the USA: the Gonococcal isolate surveillance project (GISP), Januarry 2006-june 2012. Sex transm infect., 89, 5-10

Lahra, M.M. 2013. Australian Gonococcal Surveillance Programme, 1 January to 31 March 2013.

Lal Patel, A., U. Chaudhry, D.Sachdev, P.N.Sachdeva, M.Bala andSaluja, D.2006. An insight into the drug resistance profile \& mechanism of drug resistance in Neisseria gonorrhoeae.Indian J. Med. Res., 134, 419-431

Li, S., X.H. Su, W.J. Le1, F.X. Jiang, B.X. Wang and Rice, P.A.2014. Antimicrobial susceptibility of Neisseria gonorrhoeae isolates from symptomatic men attending the Nanjing sexually transmitted diseases clinic (2011-2012): genetic characteristics of isolates with reduced sensitivity to ceftriaxone. BMC Infect. Dis., 14, 622-671

MINSANTE (Ministère de la Santé Publique). 2007. Politiques, normes et directives nationales pour la prise en charge syndromique des infections sexuellement transmissibles au Cameroun. Ministère de la santé publique, Direction de la lutte contre la maladie. Février 2007. 60 pages.

Ndowa, F.J., M.J. Francis, A. Mchiha, H. Faye-Ketteand Fonkoua, M.C. 2013. Gonococcal antimicrobial resistance: perspectives from the african region. Sex transm infect., 89, 11-15

Ohnishi, M., D. Golparian, K. Shimuta, T. Saika, S.Hoshina,K.Iwasaku,N. Shuichi,J.Kitawaki, and Unemo, M. 2011. Is Neisseria gonorrhoeae initiating a future era of untreatable gonorrhea? Detailed characterization of the first strain with high-level resistance to ceftriaxone. Antimicrob Agents Chemother., 55, 3538-3545.

REMIC (Référentiel en microbiologie médicale). 2010. SociétéFrançaise de 
Microbiologie. 5ème édition, 370 pages

Sethi, S., D. Golparian, M. Bala, D. Dorji, M. Ibrahim, K. Jabeen and Unemo, M. 2013. Antimicrobial susceptibility and genetic characteristics of Neisseria gonorrhoeae isolates from India, Pakistan and Bhutan in 2007-2011. BMC Infect. Dis., 13, 35

Supriya, D.M., I. Maclean, J.O. NdinyaAchola, A. Ndinya, S. Moses, I. Martin, A. Ronald, L. Agunde, R. Muguru, R.C. Bailey, J. Melendez and Zenilman, J.M. 2011. Emergence of Quinolone Resistance and Cephalosporin MIC Creep in Neisseria gonorrhoeae Isolated from a Cohort of Young Men in Kimusu, Kenya, 2002 to 2009. Antimicrobl. Agents Chemother., 55, 3882-3888.

Tapsall, J.W. 2009. Neisseria gonorrhoeaeand emerging resistance to extended spectrum cephalosporins. Curr. Opin. Infect., 22, 87-91.

Unemo, M., D. Golparian, G. Syversen, D.F. Vestrheim and Moi, H. 2010. Two cases of verified clinical failures using internationally recommended first-line cefixime for gonorrhoea treatment, Norway. Eur. Surveill.15, 19721.
Unemo, M., D. Golparian, R. Nicholas, M. Ohnishi, A. Gallay, and Sednaoui, P. 2012. High-level cefixime- and ceftriaxone-resistant Neisseria gonorrhoeae in France: novel penA mosaic allele in a successful international clone causes treatment failure. Antimicrob. Agents Chemother., 56, 1273-1280.

Whiley, D.M., N. Goire, M.M. Lahra, B.Donovan, A. E.Limnios, M. D.Nissen, and Sloots,T. P. 2012. The ticking time bomb: escalating antibiotic resistance in Neisseria gonorrhoeae is a public health disaster in waiting. J. Antimicrob. Chemother., 67, 2059-61

WHO (World health organization). 2012.Global Action plan to control the spread and impact of antimicrobial resistance in Neisseria gonorrhoeae. WHO1-36.Avaible:

http://www.who.int/reproductivehealth /publications/rtis/9789241503501/en/. acessed on november $29^{\text {th }} 2015$.

WHO. 1990. Global surveillance network for gonococcal antimicrobial susceptibility. Geneva, WHO/VDT. 90-452.

\section{How to cite this article:}

Ariane Nzouankeu, Antoinette Ngandjio, Carole Tayimetha, Gaëlle Tchouwa, Marcelle Abanda, Esther Sokeng, Marie-Christine Fonkoua. 2016. Trends in Gonococcal Antimicrobial Resistance in Cameroon: Before and After the Launching of the Gonococcal Antimicrobial Surveillance Program. Int.J.Curr.Microbiol.App.Sci. 5(12): 182-194.

doi: http://dx.doi.org/10.20546/ijcmas.2016.512.020 